\title{
Workshop
}

\section{Introduction: Nutrient and Water Management Practices for Improving Crop Growth, Yield, and Quality Workshop}

\author{
Kent D. Kobayashi ${ }^{1}$
}

$\mathrm{P}$ lant nutrient management and irrigation practices are crucial in helping achieve optimal crop growth, yield, quality, and grower profitability (Mikkelsen, 2011). As the availability of suitable land for crop production decreases and the concern for adequate water increases, more efficient methods of irrigation are needed (De Pascale et al., 2011). To improve agricultural sustainability in Hawaii, growers need to rely more on locally produced amendments and less on out-of-state inputs in their fertility program. Common organic amendments that can be used in conventional and organic vegetable production directly affect soil characteristics, nutrition, and biological properties, and as such, their nutrient contribution needs to be calculated.

The objective of this workshop was to have a forum to exchange ideas and information on plant nutrient and water management. These workshop papers provide a diverse range of topics in nutrient and water management with insights into some key Hawaii and Florida practices, sites of the current and future ASHS conferences. The papers cover rootstock and irrigation effects on 'Gala' apple mineral nutrition, growth, fruit quality, and yield in Idaho; use of locally produced inputs to improve crop growth, quality, and grower profitability in Hawaii; and a fertility program for vegetables with organic amendments and inorganic fertilizers in Florida.
The paper on rootstock and irrigation integrates irrigation methods and rootstock vigor as they affect mineral nutrients and apple tree growth, fruit yield, and quality. The relationships between tree growth, fruit quality attributes, yield, and mineral nutrients are detailed.

In the paper on locally produced inputs in Hawaii, factors that influence the quality, application, efficacy, and cost-effectiveness of locally produced composts, vermicomposts, rendered animal products, and algae are discussed. Aqueous extracts of vermicomposts and thermophilic composts can effectively improve crop growth and reduce costs associated with the use of these inputs.

The vegetable fertility program paper looks at organic amendments used in conventional and organic vegetable production in Florida, including cover crops, compost, and animal manure, and how they affect soil properties, nutrients, and microbial biomass. When considered as part of nutrient sources in a fertility program, their nutrient contributions should be considered.

The papers from this workshop highlight some leading research and practices and help provide insights into further research and studies.

\section{Literature cited}

De Pascale, S., L.D. Costa, S. Vallone, G. Barbieri, and A. Maggio. 2011. Increasing water use efficiency in vegetable crop production: From planting to irrigation systems efficiency. HortTechnology 21:301-308.

Mikkelsen, R.L. 2011. The " $4 \mathrm{R}$ " nutrient stewardship framework for horticulture. HortTechnology 21:658-662.

\footnotetext{
Tropical Plant and Soil Sciences Department, University of Hawaii at Manoa, 3190 Maile Way, St. John 102, Honolulu, HI 96822

This paper was part of the workshop "Nutrient and Water Management Practices for Improving Crop Growth, Yield, and Quality" held 26 Sept. 2011 at the ASHS Conference, Waikoloa, HI, and sponsored by the Plant Nutrient Management (PNM) Working Group.

${ }^{1}$ Corresponding author. E-mail: kentko@hawaii.edu.
} 